\title{
Reformas estructurales en Argentina: condiciones de implementación y efectos sociales*
}

\author{
Structural reforms in Argentina: conditions of implementation and \\ social effects
}

Reformas estruturais na Argentina: Condições de implementação e efeitos sociais

Recibido el 8 de julio de 2015. Aceptado el 26 de abril de 2016

Gonzalo Seid**

Argentina

Para citar este artículo:

Seid, Gonzalo (junio, 2016).

Reformas estructurales en

Argentina: condiciones de

implementación y efectos

sociales. Ánfora, 23(40), 195

221. Universidad Autónoma de

Manizales. ISSN 0121-6538.

\section{Resumen}

Objetivo: caracterizar el proceso de implementación y los efectos de las reformas estructurales de los años noventa en América Latina, con énfasis en el caso de Argentina. Metodología: se hizo análisis documental basado en la exploración de investigaciones sobre la temática y la consulta de los estudios más citados por éstas. Para ello, se establecieron las condiciones económicas y políticas previas en las cuales se gestó el consenso en la necesidad de reformas estructurales y se identificaron los efectos de las reformas sobre la estructura social. Las categorías de análisis principales fueron: condiciones previas que posibilitaron las reformas, proceso político de implementación y efectos

\footnotetext{
* Este artículo es producto de la tesis doctoral en curso, titulada "Trayectorias de clase social: el papel de distintas especies de capital", para el Doctorado en Ciencias Sociales de la Universidad de Buenos Aires.

** Licenciado en Sociología. Universidad de Buenos Aires. Becario doctoral Consejo Nacional de Investigaciones Científicas y Técnicas. Buenos Aires, Argentina. Correo electrónico: gonzaloseid@gmail. com
} 
sociales de las reformas. Resultados: se evidenció el papel de la inestabilidad económica de los años setenta y ochenta para la aceptación de las ideas que propugnaban la realización de cambios drásticos. El proceso político de implementación de las reformas en Argentina se caracterizó por un gobierno sin resistencias fuertes, que permitió un avance rápido y sin obstáculos. Los efectos de las transformaciones económicas en la estructura social fueron de polarización y segmentación, fundamentalmente mediante los cambios en el mercado laboral. Conclusiones: las reformas pueden entenderse como un proceso de transición, porque fueron la forma política como se concretó un cambio de matriz en la relación entre Estado, mercado y sociedad civil.

Palabras Claves: Reformas estructurales, Economía, Políticas, Mercado, Estado, Estructura social.

\section{Abstract}

Objective: to characterize the process of implementation and the effects of the structural reforms of the nineties in Latin America focused on Argentina. Methodology: a documentary analysis based on exploring research on this subject and checking the most cited studies was carried out. To this end, previous economic and political conditions in which there was a consensus on the need for structural reforms was established and the effects of reforms in the social structure were identified. The categories of analysis were: preconditions that enabled reforms, political process of implementation and social impact of reforms. Results: the role of the economic instability in the seventies and eighties for the acceptance of the ideas that involved drastic changes was evident. The political process of implementing reforms in Argentina was characterized by a government without strong resistance, which allows for a rapid and unimpeded progress. The effects of the economic transformations in the social structure were polarized and segmented, mainly, through changes in the labor market. Conclusions: reforms can be understood as a process of transition because they were the political form to establish a change in the relationship among state, market and civil society.

Keywords: Structural Reforms, Economy, Policies, Market, State, Social Structure. 


\section{Resumo}

Objetivo: caracterizar o processo de implementação e os efeitos das reformas estruturais dos anos noventa na América Latina, com ênfase no caso da Argentina. Metodologia: realizou-se uma análise documental baseada na exploração de investigações sobre a temática e a consulta dos estudos mais citados por estas. Para isso, estabeleceram-se as condições econômicas e políticas prévias nas quais o consenso foi concebido sobre a necessidade de reformas estruturais e se identificaram os efeitos das reformas na estrutura social. As categorias de análise foram: condições prévias que possibilitaram as reformas, processo político de implementação e efeitos sociais das reformas. Resultados: evidenciou-se o papel da instabilidade econômica dos anos setenta e oitenta para a aceitação das ideias que propugnavam a realização de mudanças drásticas. O processo político de implementação das reformas na Argentina se caracterizou por um governo sem resistências fortes, o que permitiu um avance rápido e sem obstáculos. Os efeitos das transformações econômicas na estrutura social foram de polarização e segmentação, fundamentalmente mediante as mudanças no mercado laboral. Conclusões: as reformas podem entender-se como um processo de transição, porque foi a forma política como se concretizou uma mudança de matriz na relação entre Estado, mercado e sociedade civil.

Palavras Chaves: Reformas estruturais, Economia, Políticas, Mercado, Estado, Estrutura social. 


\section{Introducción}

Las reformas estructurales son transformaciones impulsadas desde el Estado y orientadas al mercado, mediante políticas como la apertura comercial, las desregulaciones, la liberalización del sector financiero y las privatizaciones de empresas públicas. Sobre el tema, se ha estudiado cuáles fueron las condiciones previas que condujeron a las reformas argentinas (Cavarozzi, 1991; Torre, 1998) y cómo las transformaciones económicas se vincularon con la polarización y segmentación de la estructura social, fundamentalmente mediante los cambios en el mercado laboral.

Las políticas de liberalización, la desarticulación de la estructura productiva industrial y el cambio en el papel del Estado tuvieron consecuencias como el aumento de las desigualdades de ingresos, la pobreza, la exclusión social, el desempleo y la precariedad laboral, que significaron un deterioro en las condiciones de vida y en las posibilidades de organización de la clase trabajadora argentina (Beccaria, 2002, 2003; Armony y Kessler, 2004; Svampa, 2005, entre otros). Puesto que existen numerosos trabajos sobre aspectos específicos de las reformas y sus consecuencias -que serán referidos en este artículo- consideramos que el aporte específico de este trabajo reside en la síntesis de los hallazgos de autores que han estudiado el asunto de las reformas estructurales.

El presente trabajo pretende ser una reconstrucción histórica sintética sobre las reformas estructurales y las transformaciones en la estructura social de la Argentina en las últimas dos décadas. Partiendo de los estudios que han realizado aportes en este tema, la cuestión de las reformas estructurales surge como un proceso histórico de transición entre una matriz socioeconómica previa y la actual. Surge entonces la pregunta ¿cómo se llevó a cabo el proceso de implementación de las reformas estructurales y cuáles fueron sus efectos en Argentina?

Para responder este interrogante, este estudio se orienta por los siguientes objetivos: indagar las condiciones económicas y políticas previas en las cuales se gestó el consenso en la necesidad de reformas estructurales, caracterizar el proceso político de implementación de las reformas estructurales en Argentina e identificar los efectos de las reformas sobre la estructura social y la vida colectiva. El propósito que está detrás de los objetivos del artículo es integrar los conocimientos acumulados en la temática. 


\section{Metodología}

La estrategia de análisis cualitativo documental se basó en la exploración de trabajos de autores reconocidos que han realizado investigaciones sobre la temática y la consulta de los libros y artículos más citados por éstos. Se seleccionaron, principalmente, aquellos aspectos presentes en varios autores, para elaborar un estado de la cuestión enfocado en los conocimientos más consensuados.

Para ello, primero se establecieron las condiciones económicas y políticas previas en las cuales se gestó el consenso en la necesidad de reformas estructurales y se identificaron los efectos de las reformas sobre la estructura social. Las categorías de análisis principales fueron: condiciones previas que posibilitaron las reformas, proceso político de implementación y efectos sociales de las reformas

Y de acuerdo con los objetivos, se organizó el material a partir de tres ejes: las condiciones económicas y políticas previas que posibilitaron las reformas, el proceso político de implementación -modalidades y actores intervinientes- y los efectos de las reformas en la estructura social y en la vida social.

Para cada dimensión se realizó una grilla con los principales aportes de los distintos autores consultados. En el eje sobre los efectos de las reformas, se utilizaron varias subdimensiones, ya que además de los efectos en los sectores sociales, la mayoría de los autores refiere a otros aspectos de la vida social que se vieron modificados, como las relaciones laborales, las formas de protesta, los lazos de representación y las identidades colectivas. Se procedió a comparar los trabajos en cada dimensión, extrayendo los elementos comunes a varios autores o de un autor de referencia cuando sus planteos no presentasen importantes divergencias con otros trabajos consultados.

\section{Resultados}

Los resultados se organizarán en tres apartados. En primer lugar, se describen las condiciones previas que desembocaron en el consenso en torno a las reformas. Luego se realizan algunas puntualizaciones respecto a las modalidades y los actores intervinientes en el proceso de implementación de las reformas en Argentina. Por último, se desarrollarán los efectos de las mismas en la estructura social argentina y los vínculos de estos procesos con las 
transformaciones en las identidades colectivas, las formas de acción colectiva y los lazos de representación política.

\section{a. ¿Cómo se llega al consenso en la necesidad de las reformas estructu- rales?}

En este apartado, se exponen las condiciones previas que desembocaron en las reformas estructurales. Muchas de estas condiciones son comunes a varios países en América Latina y refieren a las recurrentes crisis económicas que expresaban el agotamiento de una matriz de relaciones entre Estado, mercado y sociedad. Se argumenta que los sucesivos fracasos de las políticas económicas implementadas y los cambios en la representación política confluyeron en el consenso en la necesidad de reformas estructurales.

Desde los años setenta, los cambios en los procesos productivos, los avances tecnológicos y la autonomización del sector financiero han sido algunos de los rasgos de la nueva etapa de globalización (French-Davis, 1997; Hirsch, 1997). Con la crisis del petróleo, como detonante, la caída en la tasa de ganancia y las presiones sobre el Estado por las tensiones sociales, se produjo la crisis del intento de compromiso de clases del keynesianismo y tuvo lugar una nueva ofensiva del capital en el mundo. Estas transformaciones, en general, tendrían consecuencias de largo alcance como el desempleo, la caída de los salarios y la flexibilización laboral, deteriorando las condiciones de vida y la capacidad de respuesta de los trabajadores (Holloway, 1994).

En América Latina, las políticas inspiradas en el neoliberalismo significarían una profundización de las desigualdades y un cambio regresivo en la estructura de clases (Portes y Hoffman, 2007). Algunas de las dictaduras de la región, particularmente las del Cono Sur, se propusieron como objetivo desarticular las instituciones de la matriz Estado-céntrica previa, considerada fuente de crisis e inestabilidad. Sin embargo, poco después de las transiciones democráticas se desmontaría dicha articulación entre Estado y mercado, constituida desde los años treinta (Cavarozzi, 1991; Torre, 1998).

La matriz Estado-céntrica se basaba en la regulación política de la economía y de los flujos de capital; la producción es para el mercado interno el núcleo dinámico de la economía. Asimismo, el espacio de la sociedad civil se había expandido con la participación y movilización de la mayoría de los sectores sociales, fundamentalmente las organizaciones de trabajadores, aunque dicha 
participación fue balanceada e incluso contrarrestada por controles políticos y culturales del Estado.

Esta matriz desembocó, en el ámbito económico, en problemas como desequilibrios en la balanza de pagos, déficit fiscales periódicos y estancamiento de la producción agrícola. En lo político, la mayor participación tendió a multiplicar y acumular las demandas, en un proceso de sedimentación y superposición de conflictos. La matriz Estado-céntrica no tuvo flexibilidad para revertir inercias y restricciones imprevistas (Cavarozzi, 1991).

Las dictaduras militares de los setenta se propusieron desmantelar la maquinaria del intervencionismo estatal a la que se adjudicaba la responsabilidad de la crisis. A partir de 1982, la crisis de la deuda de los países latinoamericanos coincidió con las transiciones políticas hacia la democratización. En este contexto de agotamiento de un modelo económico social, los procesos de transición a las democracias políticas imprimieron particulares modalidades a las transformaciones en curso (Torre, 1998).

Durante los ochenta continuaron los procesos incontrolados de deterioro económico, que dieron lugar a intentos de ajuste cada vez más extremos. Para manejar las crisis las políticas tradicionales se tornaron menos útiles por no resolver los problemas o, en ocasiones, por agravarlos. El colapso de los mecanismos de regulación estatal y los instrumentos para promover el consenso social, conformaron un patrón de "ajuste caótico" (Cavarozzi, 1991), que agudizó los efectos del agotamiento de la matriz en cuanto a la recesión y la marginalidad económica y social. La intensificación de la crisis fiscal, la cronicidad de los déficits en la balanza de pagos, la reducción de las inversiones privadas, la fuga de capitales, la alta inflación, la participación menor en el comercio y el flujo mundial de capitales, la desintegración de los actores colectivos y de la adhesión a proyectos, así como el descrédito generalizado y crónico de los gobiernos centrales, configuraron un escenario político en el que se instaló una emergencia por la crisis.

Los primeros planes de estabilización de comienzos de los ochenta, consistieron en ajustes gradualistas y de corto plazo. Luego, prevalecieron las posturas que sostenían la necesidad de una estabilización para lograr un corte drástico con la inflación inercial y revertir las expectativas. Aunque las medidas coyunturales pudieran ser exitosas en el corto plazo para permitir un alivio fiscal temporario, eran insuficientes para impedir que, con el tiempo, se prolongaran los desequilibrios y la brecha fiscal (Torre, 1998). 
El deterioro en la efectividad de las políticas económicas aceleró el desgaste político de las nuevas democracias, con la rotación vertiginosa de las opciones políticas y el deterioro de los sistemas de partidos. Ante la decepción respecto a la capacidad de los gobiernos democráticos para resolver los crecientes problemas, tiende a surgir un repliegue de la mayoría de la población respecto de la política y un "vaciamiento" de la democracia, que hace que las instituciones pierdan relevancia en la vida cotidiana, en la definición de cuestiones colectivas significativas y en su resolución (Cavarozzi, 1991).

A partir del "aprendizaje negativo" (Torre, 1998), derivado del fracaso de los ajustes que se aplicaron como respuestas a la crisis económica, se descartaron de los instrumentos y políticas existentes y fue más verosímil el diagnóstico neoliberal en las elites dirigentes y gubernamentales. La perspectiva del neoliberalismo económico sostenía que las dificultades para estabilizar las economías de la región, la crisis fiscal y las presiones inflacionarias se debían al comportamiento de las instituciones económicas con un patrón de desarrollo hacia adentro, proteccionista y con alto gasto público. Por ende, las medidas debían ser mucho más amplias y profundas que las emprendidas hasta el momento.

Para resolver la crisis se consideraba necesario encarar cambios drásticos: reformas estructurales que convirtiesen un Estado que se concebía como gigante y débil en otro más pequeño y fuerte (Torre, 1998). La opción de los gobiernos por las reformas también estuvo influida por el objetivo de generar confianza en los círculos financieros internos para evitar la fuga de capitales, en un contexto de shock externo y de necesidad de renegociar la deuda externa. Las reformas facilitaban la obtención de asistencia financiera, el refinanciamiento de la deuda y el respaldo de acreedores internacionales y grupos económicos locales.

La desafección política y la “crisis de representación” de principios de los noventa fueron relevantes en el proceso político de implementación de las reformas estructurales. El debilitamiento y la fragmentación de identidades sociales como organizaciones de clase y grupos de interés, implicaron que, en lo político, de la tradicional representación de partidos y organizaciones de intereses, se pasara a la representación soberana de líderes personalistas.

No habiendo ya una voluntad o interés preexistente, las nuevas identidades se constituyeron por escenificación, mediante la construcción de imágenes y figuras capaces de movilizar. "Representar es, desde entonces, la prerrogativa 
del poder depositada en un líder" (Novaro, 1995, p. 152) y, por lo tanto, el líder es el principal portador de la voluntad política reformista.

Para lograr las transformaciones del Estado y la sociedad, se requería que los cambios en las políticas estatales se aplicaran lo antes posible. Con el énfasis en la urgencia, quedaba legitimada la excepción, esto es, la toma de decisiones rápidas y precipitadas soslayando instancias institucionales como los debates parlamentarios. Se evidenció el fenómeno de la "democracia delegativa" $(\mathrm{O}$ ' Donnell, 1997, p. 3) en el que los "hombres clave" -generalmente líderes de movimientos de tradición popular- gobiernan discrecionalmente a partir de una legitimidad fundada en una promesa redentora, con un estilo de gestión conocido como "decretismo", por la habitualidad que adquieren los decretos presidenciales y la preeminencia del ejecutivo en la adopción de políticas de reforma.

Así, se percibe que la "misión" del líder carismático -encarnación del mandato popular- se vería obstaculizada si funcionaran rigurosamente las instituciones republicanas y la rendición de cuentas horizontal.

En suma, los problemas fiscales y externos de los ochenta, así como las limitaciones del paradigma de desarrollo precedente para ofrecer soluciones a la emergencia económica, fueron decisivos para la opción por las reformas estructurales. Por eso, más que por una opción ideológica bien definida, las medidas se adoptaban por una actitud pragmática en el marco de un clima de época.

La situación de crisis colectivamente percibida instaló un sentido de la urgencia y una demanda de nuevas iniciativas de gobierno que abrió paso a la aceptación de decisiones extraordinarias y a la ampliación de los márgenes de acción del gobierno, sobre todo de su vértice. El hecho de que los partidos políticos dejaran de representar grupos sociales, para que fueran los líderes quienes contribuyeran a producir los clivajes con los que pretendieron movilizarse, resulta de importancia en el proceso de aceptación social de las reformas estructurales.

Reseñadas las principales condiciones previas que desembocaron en que las reformas se impongan como una necesidad imperiosa, en el siguiente apartado nos aproximamos a los principales rasgos del proceso político de implementación de las reformas en Argentina, las modalidades que asumió y los actores intervinientes. 


\section{b. ¿Cómo se concreta la implementación de reformas estructurales en Argentina?}

En la Argentina de la década del noventa, las reformas estructurales orientadas al mercado consistieron en una serie de transformaciones impulsadas desde el Estado nacional. Éstas, incluyeron políticas como la apertura comercial, liberalización del sector financiero, desregulaciones del mercado, privatizaciones de empresas públicas, flexibilización de la contratación laboral, cese de subsidios a la industria y cambios tributarios.

La reestructuración del Estado incluyó además la descentralización administrativa y el traslado de competencias en áreas de salud y educación a los niveles provincial y municipal, la desregulación de obras sociales (cobertura médica) y la reforma del sistema previsional que pasó del sistema público de reparto a un régimen de capitalización individual por medio de empresas aseguradoras privadas.

Las reformas se aplicaron con un ritmo acelerado que se explica por la percepción de urgencia y la necesidad del gobierno de "sobreactuarse" para resultar creíble y ganar confianza (Torre y Gerchunoff, 1996). El hecho de que sea un gobierno peronista el promotor político de la apertura y desregulación es la novedad que permite comprender el modo en que se desarrollaron las reformas y las débiles resistencias iniciales a las mismas.

Asimismo, las reformas estructurales y la renegociación de la deuda externa generaron las condiciones de posibilidad del Plan de Convertibilidad, eje de la política económica de los noventa (Abeles, 1999; Schorr et al., 2002). En el proceso de cambio, los beneficios provisorios de las reformas y la nueva política económica superaron los costos transicionales (Palermo, 1999). Con esto se logró, momentáneamente, la esperada estabilización económica, cierto nivel de crecimiento, la recuperación de la confianza y se fortaleció la viabilidad política de la transición.

Con la consumación del cambio y las nuevas reglas de juego, se pusieron de manifiesto los altos costos de las reformas, que a pesar de que atentaban contra los intereses de los sectores populares, habían logrado ser impuestas sin mayor resistencia. Esto, debido a la autonomía gubernamental devenida de la crisis y la desarticulación previa de la posibilidad de formación de una coalición opositora (Paramio, 1999). 
Coaliciones opositoras no se formaron porque los grupos de interés que se verían afectados, como los sindicatos, ya estaban reducidos a cierta impotencia por el efecto de la inflación descontrolada; no contaban con capacidad suficiente para bloquear las reformas y habían perdido capacidad de representación (Paramio, 1999). En ese proceso -común a varios países de América Latina-con la descomposición social y el sentimiento social de emergencia ante la crisis aparecen los hiperliderazgos de los gobernantes reformadores, que no se enfrentan a coaliciones preconstituidas a favor o en contra sino a grupos desarticulados, a partir de los cuales tratan de definir una coalición de apoyo. En Argentina, los conflictos potenciales que suponen las reformas fueron controlados "gracias a la inclusividad peronista” (Palermo y Novaro, 1996, p. 332).

La inclusividad del peronismo, no significó una amenaza para el ajuste sino que posibilitó que los cambios fueran implementados con éxito. Las reformas no encontraron oposición consistente y unificada en las organizaciones sindicales; incluso, algunos sectores del sindicalismo apoyaron y colaboraron con el programa reformista del gobierno. El sector sindical en colaboración con el gobierno cedía en la lucha por la distribución del ingreso y en la necesidad de flexibilización laboral bajo el argumento de que el sacrificio era necesario para generar inversiones.

Un segundo sector sindical no apoyaba las políticas reformistas de modo general, pero lo hacía para negociar en cada caso puntual las iniciativas y luego respaldarlas u oponerse. La distribución de alicientes y beneficios clientelísticos del gobierno, por ejemplo con el manejo de los fondos de las obras sociales (entidades sindicales para la cobertura de salud), le permitió cooptar numerosos dirigentes e incorporarlos a los equipos de conducción y privatización de empresas.

El poder de los sindicatos se vio afectado tanto en su papel en el Partido Justicialista y en el gobierno, como en su carácter de referentes del reclamo laboral. Sólo un sector sindical confrontó e intentó resistir las medidas de reforma, ante lo cual el gobierno respondió ofensivamente mostrando que no estaba dispuesto a negociar bajo la presión de medidas de fuerza. Parte de este campo sindical de la confrontación acabaría por separarse de la Confederación General del Trabajo (CGT) y conformaría la Central de Trabajadores de la Argentina (CTA) en 1992, central alternativa que permitía la afiliación de desempleados y trabajadores precarizados. 
La fortaleza del liderazgo de Menem, la fragmentación del sindicalismo y la capacidad de utilizar mecanismos para persuadir o disuadir a los reticentes, le permitieron al gobierno usar eficazmente su capital político para concretar las reformas. El capital político que el presidente invirtió estaba fundado en sus credenciales peronistas frente a las bases del movimiento. Las políticas de reforma fueron formuladas para generar confianza en los sectores económicos predominantes, pero en la estrategia del gobierno ello se complementaba con las interpelaciones a las bases peronistas resignificando la historia e identidad del movimiento (Palermo y Novaro, 1996).

La fuerza e identidad política peronista seguía existiendo con mayor cohesión institucional y menor dependencia de estructuras sindicales, pero se habían cortado los lazos de la coalición de actores del movimiento populista. En la nueva etapa democrática la figura de la "gente" se había impuesto sobre la noción de “pueblo” ligada a la tradición nacional-popular (Vommaro, 2006). En la década del noventa, se redefinió la identidad peronista "en clave no antagónica con los sectores neoliberales, los intereses de los empresarios y de los operadores financieros" (Palermo y Novaro, 1996, p. 382).

De la identidad por alteridad, del peronismo clásico, se pasaba a la identidad por escenificación. Se debilitó la raigambre social de la identidad política peronista, que proporcionaba cohesión interna a la clase obrera y enlazaba intereses sectoriales y actitudes políticas. Los clivajes sociales dejan de traducirse claramente en alineamientos políticos y "las identidades personales no se desprenden como una consecuencia o una prolongación de identidades sociales mayores o colectivas" (Svampa, 2000, p. 154). "En consecuencia, podrán votar como electores peronistas, pero no tanto como obreros peronistas" (Palermo y Novaro, 1996, p. 394).

El gobierno no se apoyaba primordialmente en la mediación de organizaciones sectoriales, sino que se entrelazaba con la sociedad interpelando a actores más heterogéneos, incluso los disgregados, mediante mecanismos articulados desde la cima del poder ejecutivo. En lugar de un sistema corporativo de negociación pública, la nueva relación de fuerzas entre empresarios y trabajadores dio lugar a la negociación de favores con los actores más poderosos que tenían acceso privilegiado al gobierno, mediante lobbies empresariales fuera de la visibilidad pública. Se vieron relegadas las demandas agregadas y de grupos de intereses organizados, de modo que los actores que no podían expresarse como lobbistas, sólo podían hacerlo en tanto opinión pública de una sociedad polimorfa, desarticulada y dispersa. 
Una de las hipótesis para vincular las transformaciones económicas y las políticas afirma que el nuevo patrón de acumulación se sostuvo en la cooptación de cuadros políticos y dirigentes sindicales para la construcción de la nueva dominación, excluyendo todo compromiso con las clases subalternas. Para lograr la cohesión del bloque de poder, el "transformismo" tuvo como ejes centrales la corrupción y los negocios comunes entre los sectores dominantes y el sistema político (Basualdo, 2001).

En la década del noventa se consolidó un bloque de poder económico integrado por diversas fracciones de la burguesía local y por los acreedores externos, mientras que las reformas estructurales permitieron el aumento en los niveles de concentración y centralización del capital. Los mercados tuvieron un alto grado de concentración de la oferta; la cúpula empresarial, aunque con un alto ritmo de rotación de las firmas que la integran, se caracterizó por la búsqueda de cuasi rentas de privilegio sustentadas en ventajas monopólicas conseguidas, no por innovación sino por mecanismos de vinculación preferencial con el Estado (Nochteff, 1994).

El caso de las privatizaciones -caracterizadas por la inflexibilidad en el cumplimiento de los cronogramas, incluso cuando se había ya atenuado la emergencia en el contexto macroeconómico- resulta paradigmático respecto del modo en que se hicieron las reformas. La premura del gobierno, que asumió como propios los intereses de los grandes grupos interesados en la compra de las empresas estatales y la alta improvisación, se vincularon con una concepción antiestatista y con la falta de transparencia en las operaciones de transferencia (Iazzetta, 1997).

Las decisiones no se sometieron a la deliberación pública parlamentaria y las negociaciones se realizaron mediante el trato directo del gobierno con los grupos económicos atraídos por los activos estatales, de manera semipública e incluso secreta, en un marco de corrupción estructural. Más allá del objetivo de reordenamiento fiscal, las privatizaciones de empresas obedecían a la intención del gobierno de dar señales a los actores económicos de la indeclinable voluntad de avanzar con las reformas.

En suma, el modo como se aplicaron las reformas en Argentina fue posible debido a factores como la agudeza de la crisis previa, el poder del gobierno peronista y la desarticulación de los sectores sociales y políticos que podrían haberlas resistido. Las reformas fueron el punto de llegada de transformaciones previas y el punto de partida de una matriz social que surgió como resultado de 
las mismas. En la siguiente sección, se sintetizan los principales aportes que se han realizado con respecto a los efectos de las reformas en las relaciones sociales.

\section{c. ¿Qué efectos tuvieron las reformas sobre la estructura social?}

El nuevo modelo económico suponía, necesariamente, un cambio profundo en el tejido social. Partiendo de los cambios en la economía, caracterizaremos las nuevas relaciones de fuerza entre distintos sectores sociales y algunos fenómenos socioculturales como las formas de protesta, los lazos de representación política y las identidades colectivas.

Las reformas estructurales son indisociables de la política económica de esta etapa para conformar el modelo económico de la convertibilidad. La política económica de los noventa en Argentina estuvo basada en la liberalización comercial y financiera y desembocó en una aguda crisis (Damill, Frenkel y Juvenal, 2003). La convertibilidad fijaba el tipo de cambio en una paridad uno a uno con el dólar y garantizaba, por ley, que los pesos argentinos en circulación equivaldrían al monto de reservas en dólares. Con la fijación del tipo de cambio nominal y el aumento de precios internos de bienes no transables en los primeros años de la década del noventa, se retrasó el tipo de cambio real.

La apertura comercial y el atraso cambiario incentivaron las importaciones y, con ello, la pérdida de competitividad de los bienes locales, generando déficit comercial. El sector público también era deficitario, por factores como la pérdida de los recursos de la seguridad social con la reforma previsional -mientras que el Estado debía continuar las erogaciones de jubilaciones, dejó de percibir los aportes jubilatorios-y la reducción de aranceles a las importaciones.

Por el bajo nivel de inversión y los déficits de los sectores público y externo, la economía pasó a depender fuertemente del endeudamiento externo. El aumento del desempleo a partir de mediados de la década y la caída de la actividad económica, agudizaron la situación y la necesidad de endeudamiento externo, a tasas cada vez más elevadas. La pérdida de confianza propició la fuga de capitales del sector privado, que junto con el peso de la deuda, erosionaron las reservas y la posibilidad de continuar el régimen de la convertibilidad (Damill, 2000).

Esta situación desembocó en el corralito bancario de 2001 que restringía la libre disposición de los depósitos y significó el fin de la convertibilidad. En síntesis, el problema de las divisas y las dificultades para convertir el ahorro interno en inversión, fueron los obstáculos decisivos del modelo de la convertibilidad, 
que colapsó con la crisis de 2001-2002, una de las más profundas de la historia argentina (Castellani y Schorr, 2004).

Como se señaló, las reformas estructurales y la convertibilidad implicaron un avance de los sectores dominantes. Con la desregulación y la apertura asimétricas de la economía y la privatización de las empresas públicas, se generaron nuevos ámbitos privilegiados de acumulación, que significaban para los sectores económicos más concentrados la obtención de cuasi rentas de privilegio otorgadas por el Estado (Azpiazu, 1994; Basualdo, 2006). Se impuso un nuevo comportamiento económico basado en la valorización financiera, lo que trajo aparejada una distribución del ingreso más regresiva y un creciente nivel de exclusión social, consolidándose así el patrón de acumulación puesto en marcha a partir de la dictadura militar, que ampliaba la brecha entre capital y trabajo (Basualdo, 2001).

Comoconsecuenciadelas reformas, seagudizóelprocesodedesindustrialización y la reestructuración regresiva del sector manufacturero local, disminuyendo la participación del sector en el Producto Bruto Interno y en la creación de puestos de trabajo. La estructura de precios y rentabilidades relativas tendió a desalentar la inversión en el ámbito manufacturero. Se incrementó el grado de oligopolización y extranjerización en el sector concentrándose la producción en un conjunto reducido de empresas.

Los principales oligopolios de la actividad estuvieron asociados a las primeras etapas del procesamiento industrial y al aprovechamiento de espacios privilegiados de acumulación de capital, tendiendo a una marcada primarización y simplificación productiva, generando menores niveles de valor agregado, eslabonamientos productivos y demanda de mano de obra. La apertura comercial indujo además una desintegración de la producción fabril local por la compra de insumos en el exterior de las firmas industriales de mayor tamaño.

La disminución de la cantidad de obreros ocupados en la actividad se vio acompañada por el deterioro de los salarios a pesar de los aumentos en la productividad de la mano de obra (Schorr, 2002). La apertura a las importaciones y la desregulación de la economía afectaron a las pequeñas y medianas empresas manufactureras locales, hasta entonces protegidas de la competencia externa. Ello provocó - por tratarse de un sector que generaba alta demanda de trabajadoresuna notable disminución de mano de obra del sector industrial. 
En relación con estos procesos, se produjo un aumento de la participación relativa del sector servicios y una creciente feminización de la población económicamente activa. El aumento de la participación del sector de servicios en la economía implicó un cambio en la composición y el poderío de la clase trabajadora, creciendo la proporción de trabajadores de servicios con menor tradición de sindicalización y mayor heterogeneidad, en detrimento del proletariado industrial fuerte y altamente sindicalizado de la fase de sustitución de importaciones (Novick, 2000).

En el mismo sentido regresivo operaron las privatizaciones de empresas públicas que, en el caso argentino, se hicieron con gran celeridad y profundidad, muchas veces sin contar con las capacidades técnicas óptimas, mediante procedimientos que no eran los más acordes a la institucionalidad democrática, sin retener sectores estratégicos rentables (Iazzetta, 1997) ni considerar efectos sociales como la pérdida de puestos de trabajo.

El atractivo del negocio de las privatizaciones era múltiple y posibilitó una convergencia de intereses: consistía en que se estaban concediendo segmentos de mercado no expuestos a la competencia, con altas tarifas, que proporcionaban rentabilidades extraordinarias casi sin riesgo empresario, a la vez que se posibilitaba a los acreedores el cobro de la deuda externa pública -así como la renegociación de la deuda restante en el marco del Plan Brady-. Una vez privatizadas, estas empresas obtuvieron elevados beneficios a costa de los consumidores, dado el carácter monopólico de los servicios públicos, las altas tarifas y la precariedad de los marcos regulatorios (Abeles, 1999).

El gobierno privatizó el sistema de jubilaciones y empresas de servicios clave, argumentando que las empresas públicas eran ineficientes y deficitarias. Se privatizaron empresas como Entel, Aerolíneas Argentinas e “incluso, un recurso estratégico como el petróleo: la privatización de Yacimientos Petrolíferos Fiscales (YPF), paradigma de las empresas estatales del país, significó no sólo la pérdida de control sobre un área crucial, sino también el disparador de la ruptura del lazo social en espacios provinciales donde YPF había desempeñado, históricamente, una considerable función contenedora” (Ansaldi, 2007, p. 553).

Las transformaciones económicas tuvieron efectos de polarización y segmentación de la estructura social, fundamentalmente mediante los cambios en el mercado laboral (Beccaria, 2002, 2003; Armony y Kessler, 2004; Svampa, 2005; Torrado, 2007; Kessler y Espinosa, 2007; Palomino, 2010; Lindenboim, 2010). Las políticas de liberalización, la desarticulación de la estructura 
productiva industrial y el cambio en el papel del Estado tuvieron consecuencias sobre la estructura social como el aumento de las desigualdades de ingresos, la pobreza, la exclusión social, el desempleo estructural y la precariedad laboral; fenómenos que implicaron un deterioro en las condiciones de vida y posibilidades de organización y lucha de distintos sectores de la clase trabajadora, en sentido amplio.

Con las reformas estructurales y sus efectos, se profundizó la progresiva "decadencia social" y la descomposición institucional de un país que desarticuló su estructura productiva y su entramado social (Pucciarelli, 1999, 2002). En un proceso común a varios países de Latinoamérica "la transformación de las estructuras sociales de nuestros países ha generado fragmentación de clases e identidades, ruptura del lazo social y, en definitiva, un tremendo deterioro de la calidad de vida, degradada, en demasiados casos, a una condición infrahumana” (Ansaldi, 2007, p. 558).

Uno de los mecanismos que tradujeron las reformas en consecuencias sociales fue el cambio en el sistema de relaciones laborales. Se modificaron los marcos legislativos con la incorporación de nuevas formas de contratación y la descentralización de los convenios colectivos, se amplió la segmentación sectorial respecto a salarios y beneficios sociales, y se volvieron más heterogéneas las orientaciones estratégicas de empresarios y sindicatos (Novick y Catalano, 1992; citado en Farinetti, 1999).

La reforma laboral incorporó las diversas modalidades de empleo temporario, la flexibilidad de los tiempos de trabajo y la introducción del período de prueba; redujo los aportes patronales y la seguridad social y modificó las normas sobre accidentes y enfermedades laborales. Durante la convertibilidad cayó la participación asalariada y cuentapropista en el producto social, mientras que el aumento de la participación capitalista en el ingreso nacional se destinó al incremento del consumo capitalista y no a la inversión privada (Lindenboim, Kennedy y Graña, 2006).

La demanda laboral disminuyó, desde comienzos de la década, por la reestructuración productiva y se agudizó con las fases recesivas de 1995 y la comenzada en 1998. La desocupación abierta pasó a ser elevada y persistente, mientras que la precarización y la inestabilidad se intensificaron sobre todo entre los ocupados de baja calificación, como consecuencia de la importancia creciente de los puestos asalariados no registrados y la menor estructuración de las ocupaciones independientes. Un creciente sector vulnerable de los trabajadores 
alternaba entre momentos breves de desocupación y puestos precarios también de duración reducida.

Las modificaciones regulatorias no sólo no aumentaron los niveles ocupacionales sino que parecen haber favorecido la extensión de la precariedad. Asimismo, se incrementaron los requerimientos educacionales exigidos por los empleadores de trabajos formales, tanto por el cambio técnico como por el fenómeno de devaluación educativa producto del desempleo generalizado. A pesar de las mejoras en la productividad y las reducciones de costos laborales no salariales, las remuneraciones en general se mantuvieron estables -aunque se amplió la diferenciación de las remuneraciones- (Beccaria, 2003; Altimir y Beccaria, 1999; Benza y Calvi, 2005).

Los sectores más empobrecidos se vieron afectados fuertemente por la marginalidad y la descalificación laboral, como consecuencia de la desocupación prolongada. Se configuró un universo fragmentado de marginalidad socioeconómica en actividades de supervivencia, compuesto por trabajadores changarines, vendedores ambulantes, feriantes, cartoneros, etc., muchos provenientes de familias de clase trabajadora que experimentaron un descenso social (Nun, 1999, 2010; Salvia y Chávez Molina, 2007; Malimacci y Salvia, 2005; Torrado, 2007).

A la par de la reducción cuantitativa de la clase obrera industrial, fue apareciendo una creciente masa de población situada fuera del mercado de trabajo, sin relación estructural con los procesos dominantes de producción, en una situación de pobreza persistente (Neffa et al., 2000). Argentina no fue ajena a la acentuación de la desigualdad social de la región latinoamericana (Ansaldi, 2007; Merklen, 1997).

En los denominados sectores medios, el empobrecimiento se tradujo en fenómenos como el empleo asalariado no registrado, la inestabilidad, la pérdida de derechos en condiciones de trabajo e incluso el crecimiento del cuentapropismo de subsistencia, otra de las formas que asumió la mano de obra sobrante para el nuevo modelo económico (Beccaria, 2003; Monza, 1996). Algunos sectores sociales que habían pertenecido a la clase media pasaron a ser "nuevos pobres" (Murmis y Feldman, 1993; Minujin y Kessler, 1995), que si bien llegaban a satisfacer necesidades básicas de tipo estructural, sus ingresos eran insuficientes para cubrir la canasta básica. 
A diferencia de los denominados pobres estructurales, grupo socialmente homogéneo y concentrado geográficamente en el cordón de barrios periféricos $\mathrm{y}$ villas miserias, los nuevos pobres se distribuyeron como una pobreza dispersa, puesto que continuaron viviendo en los barrios de clase media. Los cambios regresivos en el mercado laboral, la retirada del Estado en distintas áreas y el deterioro de la calidad de educación y salud públicas confluyeron en la erosión de su nivel de vida (Lvovich, 2000).

En las transformaciones sociales y del mercado de trabajo incidieron múltiples aspectos de la vida social como las formas de protesta (Battistini, 2002). A comienzos de la década disminuyó la cantidad de protestas laborales y se registró un desplazamiento relativo de los conflictos laborales del área industrial hacia el sector servicios. La alta desocupación y la amenaza de despido que conlleva impactaron en la disminución de las protestas sindicales clásicas. Desde 1995, el impacto del efecto tequila puso de manifiesto los costos de la política económica ante la percepción social y comienzan a intensificarse las protestas, pero frente a las huelgas y movilizaciones del repertorio clásico de la protesta laboral, cobran relevancia nuevas formas como los "estallidos sociales" en el interior del país y los cortes de ruta.

En estas nuevas formas no prima un lenguaje de clase ni un anclaje identitario fuerte y tiende a renegarse de las identificaciones políticas. Las protestas suelen ser focalizadas, fragmentadas organizativamente y poco articuladas entre sí, con formas menos institucionalizadas y más espontáneas, mientras que las reivindicaciones son más puntuales, defensivas y orientadas a la satisfacción de necesidades básicas. Las reformas afectaron los recursos y las oportunidades para reclamar, pero también modificaron criterios y pautas de comportamiento ligados a la matriz social, económica y estatal que se había desarticulado (Farinetti, 1999).

Ciertas transformaciones sociales que coadyuvaron para que sean posibles las reformas, a la vez se vieron reforzadas con su implementación. En el proceso de transformación de las clases sociales y disolución de antiguos actores colectivos con poder de negociación y anclaje en la sociedad, tienen lugar profundos cambios en los lazos de representación, los partidos y las identidades políticas, que tienden al debilitamiento de los clivajes políticos, desdibujando barreras de distinción (Novaro, 1994, 1995, 1999; Palermo y Novaro, 1996; Torre, 2003; Levitsky, 2005; Svampa, 2000). 
Con el deterioro de los tradicionales mecanismos de representación y la creciente gravitación de la “opinión pública” en la política (Quiroga, 2006), se fue constituyendo una nueva forma de democracia, designada por O’Donnell (1997) como democracia delegativa, crucial en la propia implementación de las reformas -y a su vez reforzada por éstas-, en un proceso caracterizado por el hiperpresidencialismo, la autonomización del poder ejecutivo, el decretismo, la personalización, la descomposición de los partidos políticos, la corporativización del sistema político y el deterioro de las identidades políticas tradicionales, teniendo lugar un conjunto de transformaciones que tendieron hacia un debilitamiento del espacio público (Pucciarelli, 2002; Borón, 1999).

El nuevo modelo de acumulación consolidado con la implementación de las reformas estructurales, logró desmontar el modelo de integración social previo, produciendo una significativa fragmentación al interior de las denominadas clases medias, debido a la brecha pronunciada entre los "ganadores y perdedores" del modelo. La identidad de clase media, caracterizada por el individualismo en las pretensiones de ascenso social, la cultura mimética y los consumos orientados a la búsqueda de distanciamiento respecto a los estratos inferiores, se vio afectada para vastos sectores por la experiencia del empobrecimiento, traduciéndose en lo subjetivo como un traumático estigma del fracaso personal.

En los sectores populares urbanos, se erosionó la conciencia obrera por factores como la tercerización de la economía, el desempleo y la pérdida de la capacidad de consumo. Se debilitaron los marcos culturales del antiguo mundo obrero, los tradicionales clivajes políticos y se incrementó su heterogeneidad social. Este proceso cobra más relevancia si se tiene presente que el peronismo había estructurado y sintetizado desde mediados del siglo XX la experiencia subjetiva de los sectores populares, uniendo lo personal y lo social en una identidad centrada en el mundo del trabajo, con compromisos políticos "totales" y que operaba como mecanismo de distinción con los sectores los medios y altos.

En el plano de las subjetividades, en la década del noventa se abre una era de identidades menos inclusivas y más parciales, volátiles y fragmentarias. Se establece una relación instrumental con los roles sociales y profesionales, mientras que los sentidos sobre los que se construyen las identidades se desplazan hacia el individuo y los consumos culturales. En estas circunstancias, se vio socavada la esperanza de los sectores populares y medios respecto a la consecución de mejoras colectivas en las condiciones de vida mediante la lucha social, política y 
sindical. Se impuso con fuerza la ideología del "sálvese quien pueda" y la ilusión de la salida individual para lograr el ascenso social o evitar el descenso. Los sujetos se volvieron más individualistas, escépticos y desencantados con lo colectivo y lo político (Scavino, 1999).

\section{Conclusiones}

En primer lugar, se puede concluir que las condiciones que produjeron el amplio consenso acerca de la necesidad de implementación de las reformas estructurales, encierran múltiples factores: desde el agotamiento de la matriz sociopolítica estadocéntrica y el régimen de acumulación centrado en el mercado interno -común a toda la región latinoamericana-, hasta las particularidades de los distintos gobiernos de cada país, pasando por los distintos tipos de transición de las dictaduras a las democracias. Los estudios realizados coinciden en el papel decisivo de las sucesivas crisis económicas y los numerosos fracasos en las políticas previas para la aceptación de las ideas que propugnaban la realización de cambios drásticos (Cavarozzi, 1991; Torre, 1998).

En segundo lugar, respecto al proceso de implementación de las reformas en el caso argentino, se concluye que la profundidad y celeridad lo que caracterizaron, se explican por la agudeza de la crisis hiperinflacionaria que las precedió, la capacidad del gobierno peronista para ejercer el liderazgo, la desmovilización de los sindicatos y la desarticulación de la oposición. Las resistencias fueron escasas, dispersas e ineficaces. La percepción de urgencia ante la crisis y de necesidad de implementar cambios profundos para salir de la misma luego de los intentos fallidos de medidas, fueron elementos que conjugados dieron lugar a una amplia aceptación de las reformas, con resistencias débiles y desarticuladas (Torre y Gerchunoff, 1996; Palermo y Novaro, 1996).

Por último, como puede apreciarse en los diversos estudios referidos, los efectos de las reformas estructurales han penetrado en múltiples dimensiones de la vida social, tanto en lo estructural como en lo simbólico, contribuyendo a transformaciones en la dinámica económica, el mercado de trabajo, la estructura de clases, el sistema político, los lazos de representación, las formas de acción colectiva, las identidades políticas y las disposiciones subjetivas. A partir de la integración del conocimiento acumulado sobre la temática, se vuelve posible interrogarse sobre las interrelaciones entre lo económico y lo político para reconstruir con una mirada integral la unidad de este proceso social, cuya 
complejidad impide circunscribirlo a la institución estatal o reducirlo a una única dimensión de análisis.

Asimismo, aunque los “costos" sociales de las reformas sean bien conocidos, cabe preguntarse en qué grado puede imputarse a estas políticas la causalidad de los procesos de deterioro social de la última década del siglo $\mathrm{XX}$, puesto que algunos de ellos venían desarrollándose con anterioridad. Más bien, se puede hipotetizar que las reformas han profundizado y llevado a su culminación tendencias de distinto tipo que las precedieron, tanto respecto a la acentuación de desigualdades sociales como respecto a las transformaciones en el funcionamiento democrático, la representación política y las identidades colectivas. Las reformas pueden entenderse como un proceso de transición porque fueron la forma política como se concretó un cambio de matriz en la relación entre Estado, mercado y sociedad civil; el cariz político de una modificación profunda en las relaciones sociales.

\section{Bibliografía}

Abeles, M. (diciembre, 1999). El proceso de privatizaciones en la Argentina de los noventa. ¿Reforma estructural o consolidación hegemónica? Época. Revista argentina de economía política, 1(1). Buenos Aires.

Altimir, O. y Beccaria, L. (1999). El Mercado de Trabajo bajo el Nuevo Régimen Económico en Argentina. Serie Reformas Económicas (28). Santiago de Chile: Naciones Unidas/CEALS.

Ansaldi, W. (2007). La novia es excelente, sólo un poco ciega, algo sorda, y al hablar tartamudea. Logros, falencias y límites de las democracias de los países del Mercosur, 1982-200”. En: ANSALDI, W. (Director). La democracia en América Latina, un barco a la deriva. Buenos Aires, Argentina: Fondo de Cultura Económica.

Armony, V. y Kessler, G. (2004). Imágenes de una sociedad en crisis. Cuestión social, pobreza y desempleo. En M. Novaro y V. Palermo (Comps.). La historia reciente. La Argentina en democracia. Buenos Aires, Argentina: Edhasa.

Azpiazu, D. (1994). La industria argentina ante la privatización, la desregulación y la apertura asimétricas de la Economía. La creciente polarización del po- 
der económico. En D. Azpiazu y H. Nochteff (1994). El desarrollo ausente. Buenos Aires, Argentina: FLACSO.

Basualdo, E. (2001). Sistema político y sistema de acumulación en la Argentina. Buenos Aires, Argentina: UNQui-FACSO-IDEP.

Basualdo, E. (2006). Estudios de historia económica argentina. Buenos Aires, Argentina: Siglo XXI.

Battistini, O. (Coord.) (2002). La atmósfera incandescente. Escrito políticos sobre la Argentina movilizada. Buenos Aires, Argentina: Asociación Trabajo y Sociedad.

Beccaria, L. (2002). Empleo, remuneraciones y diferenciación social en el último cuarto del siglo XX. En VVAA Sociedad y sociabilidad en la Argentina de los 90. Buenos Aires, Argentina: Biblos.

Beccaria, L. (agosto, 2003). Las vicisitudes del mercado laboral argentino luego de las reformas. Boletín Informativo Techint, (312).

Benza, G. y Calvi, G. (2005). Concentración del ingreso y desigualdad social en la Argentina (1974-2003). Realidad Económica, (214), pp. 74-104.

Borón, A. (1999). Pensamiento único y resignación política. En A Boron et. al. Tiempos violentos. Buenos Aires, Argentina: FLACSO-Eudeba.

Castellani, A., Schorr, M. (diciembre, 2004). Argentina: convertibilidad, crisis de acumulación y disputas en el interior del bloque de poder económico. Cuadernos del CENDES, pp. 55-81.

Cavarozzi, M. (diciembre, 1991). Más allá de las transiciones a la democracia en América Latina. Revista de Estudios Políticos (Nueva Época), (74).

Damill, M. (septiembre, 2000). El balance de pagos y la deuda externa pública bajo la convertibilidad. Boletín Informativo Techint, (303).

Damill, M., Frenkel, R. y Juvenal, L. (2003). Las cuentas públicas y la crisis de la convertibilidad en Argentina. Desarrollo Económico, 43(170), pp. 203-230. 
Farinetti, M. (septiembre, 1999). ¿Qué queda del “movimiento obrero"? Las formas del reclamo laboral en la nueva democracia argentina. Trabajo y Sociedad $1(1)$.

French-davis, R. (marzo, 1997). Alcances económicos de la globalización. Nueva Sociedad, (147), Caracas, Venezuela.

Hirsch, J. (mayo, 1997). ¿Qué es la globalización? Realidad Económica, (147), Buenos Aires, Argentina.

Holloway, J. (1994). Marxismo, Estado y capital: la crisis como expresión del poder del trabajo. Fichas temáticas de Cuadernos del Sur. Editorial Tierra del Fuego.

Iazzetta, O. (septiembre, 1997). Capacidades técnicas y de gobierno en las privatizaciones de Menem y Collor de Melo. Desarrollo Económico, 37(146).

Kessler, G. y Espinoza, V. (2007). Movilidad social y trayectorias ocupacionales en Buenos Aires. Continuidades, rupturas y paradojas. En R. Franco, A. León, R. Atria (Coords.) Estratificación y movilidad social en América Latina. Transformaciones estructurales de un cuarto de siglo. Santiago de Chile: LOMCEPAL-GTZ.

Levitsky, S. (2005). La transformación del justicialismo: del partido sindical al partido clientelista. 1983-1999. Buenos Aires, Argentina: Siglo XXI.

Lindenboim, J. (2010). Ajuste y pobreza a fines del siglo XX. En S. Torrado. El costo social del ajuste (Argentina 1976-2002), Tomo II. Buenos Aires, Argentina: Edhasa.

Lindenboim J., Kennedy, D., Graña, J. M. (2006). Distribución, consumo e inversión en la Argentina a comienzos del siglo XXI. Realidad Económica, pp. $65-92$.

Lvovich, D. (2000). Colgados de la soga. En M. Svampa (Ed.). Desde abajo. La transformación de las identidades sociales. Buenos Aires, Argentina: Biblos.

Mallimaci, F. y Salvia, A. (2005). (Comps.). Los Nuevos Rostros de la Marginalidad. Buenos Aires, Argnetina: Biblos. 
Merklen, D. (1997). Un pobre es un pobre. La sociabilidad en el barrio; entre las condiciones y las prácticas. Sociedad, (11), pp. 21-64.

Minujin, A. y Kessler, G. (1995). La nueva pobreza en la Argentina. Buenos Aires, Argentina: Planeta.

Monza, A. (1996). Evolución reciente y perspectivas del mercado de trabajo en la Argentina. Aportes, (5), Buenos Aires, Argentina.

Murmis, M. y Feldman, S. (1993). Heterogeneidad social de la pobreza. En A. Minujín (Ed.) Cuesta abajo. Buenos Aires, Argentina: UNICEF-Losada.

Neffa, J. et.al. (2000). Exclusión social en el mercado del trabajo. El Caso de Argentina. Serie Exclusión Social - Mercosur, (109). Santiago de Chile: OIT-Fundación Ford.

Nochteff, H. (1994). Los senderos perdidos del desarrollo. Elite económica y restricciones al desarrollo en Argentina. En D. Azpiazu y H. Nochteff. El desarrollo ausente. Restricciones al desarrollo, neoconservadurismo y elite económica en la Argentina. Ensayos de economía política. Buenos Aires, Argentina: FLACSO.

Novaro, M. (1994). Pilotos de tormentas. Crisis de representación y personalización de la política. Buenos Aires,Argentina: Letra Buena.

Novaro, M. (junio, 1995). El debate contemporáneo sobre la representación política. Desarrollo Económico, 35(137).

Novaro, M. (1999). Crisis y renovación de los partidos. Una perspectiva comparada sobre los años del menemismo. En VVAA: Entre el abismo y la ilusión. Buenos Aires, Argentina: Norma.

Novick, M. (2000). Reconversión segmentada en la Argentina: empresas, mercado de trabajo y relaciones laborales a fines de los ' 90 ". En De la Garza Toledo (Comp.). Reestructuración productiva, mercado de trabajo y sindicatos en América Latina. Buenos Aires, Argentina: CLACSO.

Nun, J. (1999). El futuro del empleo y la tesis de la masa marginal. Desarrollo Económico, 38, (52), Buenos Aires, Argentina. 
Nun, J. (2010). Sobre el concepto de masa marginal. Revista Lavboratorio, 11 (23).

O'donnell, G. (1997). Democracia Delegativa. En O'donnell, G. Contrapuntos. Ensayos Escogidos sobre Autoritarismo y Democratización. Buenos Aires, Argentina: Paidos.

Palermo, V. (1999). ¿Mejorar para empeorar? La dinámica política de las reformas estructurales argentinas. En VVAA Entre el abismo y la ilusión. Peronismo, democracia y mercado. Buenos Aires: Norma.

Palermo, V. y Novaro, M. (1996). El menemismo como horizonte neoperonista. En: Palermo, V. y Novaro, M. Política y poder en el gobierno de Menem. Buenos Aires, Argentina: Ed. Norma.

Palomino, H. (Dir.) (2010). La nueva dinámica de las relaciones laborales en Argentina. Buenos Aires, Argentina: Jorge Baudino.

Paramio, L. (1999). Las dimensiones políticas de las reformas económicas en América Latina. Documento de trabajo. Zona Abierta, 88-89.

Portes, A. y Hoffman, K. (2007). Las estructuras de clase en América Latina: composición y cambios en la época neoliberal. En Franco, R; León, A; Atria, R. (Coords.) Estratificación y movilidad social en América Latina. Transformaciones estructurales de un cuarto de siglo. Santiago de Chile: LOMCEPAL-GTZ.

Pucciarelli, A. (1999). ¿Crisis o decadencia? Hipótesis sobre el significado histórico de algunas transformaciones recientes de la sociedad argentina. Estudios sociológicos, $X V I I(49)$. México

Pucciarelli, A. (2002). La democracia que tenemos. Declinación económica, decadencia social y degradación política en la Argentina actual. Buenos Aires: Libros del Rojas.

Quiroga, H. (2006). Arquitectura de un gobierno de la opinión pública. En I. Cheresky (Comp.) La política después de los partidos. Buenos Aires, Argentina: Prometeo. 
Salvia, A. y Chávez Molina, E. (Ed.) (2007). Sombras de una marginalidad fragmentada. Aproximaciones a la metamorfosis de los sectores populares de la Argentina. Buenos Aires, Argentina: Miño y Dávila.

Scavino, D. (1999). La era de la desolación. Ética y moral en la Argentina de fin de siglo. Buenos Aires, Argentina: Manantial.

Schorr, M. (2002). Mitos y realidades del pensamiento neoliberal: la evolución de la industria manufacturera argentina durante la década de los noventa. En Schorr, M. et. al. Más allá del pensamiento único. Hacia una renovación de las ideas económicas en América Latina y el Caribe. Buenos Aires, Argentina: $\mathrm{CLACSO}$ /UNESCO.

Svampa, M. (Ed.) (2000). Desde abajo. La transformación de las identidades sociales. Buenos Aires: Biblos.

Svampa, M. (2005). La fragmentación de las clases medias. La nueva configuración social. En La sociedad excluyente. La Argentina bajo el signo del neoliberalismo. Buenos Aires: Taurus.

Torrado, S. (comp.) (2007). Población y Bienestar Social en Argentina del Primero al Segundo Centenario. Una historia social del siglo XX, Tomo I. Buenos Aires, Argentina: Ed. EDHASA.

Torre J. C. (1998). El proceso político de las reformas económicas en América Latina. Buenos Aires, Argentina: Paidós.

Torre, J. C. (2003). Los huérfanos de la política de partidos. Sobre los alcances y la naturaleza de la crisis de representación partidaria”. Desarrollo Económico, 42(168).

Torre, J. y Gerchunoff, P. (diciembre, 1996). La política de liberalización económica en la administración de Menem. Desarrollo Económico, (143). Buenos Aires, Argentina.

Vommaro, G. (2006). Cuando el pasado es presente: las elecciones presidenciales de 1983 y la construcción de un nuevo tiempo político en la Argentina. En A. Pucciarelli (Coord.). Los años de Alfonsín. ¿El poder de la democracia o la democracia del poder? Buenos Aires, Argentina: Siglo XXI. 